\title{
BIODISPONIBILIDADE DE ZINCO EM DIETA REGIONAL DE MANAUS, AM. ESTUDO EM RATOS.
}

\author{
Lucia ㅈ. O. YUYAMA', Silvia M. F, COZZOLINO²
}

\begin{abstract}
RESUMO - Foi estudada a biodisponibilidade de zinco em ratos recebendo uma dieta regional de Manaus, AM. A dieta foi elaborada segundo os dados de SHRIMPTON \& GIUGLIANO, (1979) para famílias com rendimentos inferiores a 2 salários mínimos. O ensaio biológico com ratos da linhagem Wistar se baseou inicialmente, na depleção de zinco e vitamina A na lactação, adaptação dos filhotes com a dieta regional por 7 dias e período de repleção onde se realizou a suplementação com zinco de acordo com as recomendações do "COMMITTEE ON LABORATORY ANIMAL DIETS" (1979), Os resultados nos permitiram concluir que a quantidade de zinco presente na dieta, avaliada pelos parâtmetrós de medida de biodisponibilidade de zinco como crescimento, concentração nos órgãos e de enzima zineo dependente, foi utilizada adequadamente pelos animais, provavelmente pelos fatores promotores da dieta.
\end{abstract}

Palavras chave: Biodisponibilidade, Zinco, Dieta regional de Matnaus.

Zinc bioavalability of a regional diet of Manaus, AM. study in rats.

ABSTRACT - Zinc bioavailability in rats receiving a regional diet of Manaus, was studied. The regional diet was elaborated according to data of SHRIMPTON \& GIUGLIANO (1979), for families receiving less than two minimum salaries. The biological test with Wistar rats was based on the depletion of zinc and vitamin A during the period of lactation, followed by the adaptation of the pup rats with regional diet of Manaus for seven days, and a period of repletion where supplements of zinc were given according to the recommendations of the COMMITTEE ON LABORATORY ANIMAL DIETS (1979). From the results it was concluded that the amount of zine present in the diet, as determined by parameters of bioavailability such as growth, concentration in the organs and zinc-dependent enzymes, was adequately used by the animals, probably due to promoting factors in the diet.

Key-words: Bioavailability, Zinc, Regional diets Manaus.

\section{INTRODUÇÃO}

$\mathrm{O}$ zinco é um elemento fundamental na expressão do potencial genético e está envolvido na esta-bilização das estruturas de protéinas, ácido nucléico e na preservação da integridade das organelas subcelulares (VALLEE \& AULD, 1990).

A primeira deficiência de zinco no homem foi relatada por PRASAD em rapazes egípcios cuja dieta consistia quase que exclusivamente de cereais (PRASAD, 1969).
A biodisponibilidade de zinco é significativamente reduzida por inibidores dietéticos como hexafosfato de mioinositol, cálcio na presença de fitato e alguns minerais como cobre e ferro (ELLIS et al., 1987; OESTREICHER \& COUSIN, 1985).

Assim, a quantidade de um mineral que está disponível para a absorção é dependente sobretudo da composição da dieta, da secreção gastroentestinal e interação luminal (MILLS, 1985).

Estudos sobre biodisponibilidade

\footnotetext{
1 Instituto Nacional de Pesquisas da Amazônia, INPA/CPCS. Alameda Cosme Ferreira 1756. Aleixo. Manaus, AM. CEP. 69083-000.

2 Faculdade de Ciências Farmacêuticas, USP. Av. Lineu Prestes, 580, CEP. 05508-900)
} 
de zinco em alimentos e dietas regionais brasileiras são escassos. Considerando a indicação da deficiência de zinco na região (SHRIMPTON et al., 1983), nos propusemos a estudar a biodisponibilidade de zinco em dieta regional de Manaus, AM.

\section{MATERIAL E MÉTODOS}

As rações à base da dieta regional de Manaus foram elaboradas segundo os dados de SHRIMPTON \& GIUGLIANO (1979), tomando-se como base o consumo médio de famílias com rendimentos até dois salários mínimos. A quantidade adicionada de zinco foi visando atender as recomendações do "COMMITTEE ON LABORATORY ANIMAL DIETS" (1979).

\section{Ensaio Biológico}

Foram utilizadas ratas adultas pós-parto, albinas da linhagem Wistar (Rathus norvergicus, var. albinus, rodentia Mammalia) com 6 filhotes machos cada, recém nascidos provenientes da colônia do biotério da Faculdade de Ciências Farmacêuticas da Universidade de Săo Paulo.

A ração à base de caseina fornecida aos animais no período de depleção, continha os nutrientes em quantidades sugeridas pelo "COMMITTEE ON LABORATORY ANIMAL DIETS “ ( 1979). A caseína utilizada foi previamente lavada com EDTA 1\% para retirada do zinco residual ( $2 \mathrm{lug} /$ g). O procedimento utilizado na lavagem da caseína seguiu as recomendações da literatura e as otimizadas no laboratório de Nutrição da Faculdade de Ciências Farmacêuticas (YUYAMA, 1993).

Após a depleção, os animais receberam a ração a base da dieta regional de Manaus por um período de 7 dias para efeito de adaptação, seguindo-se o período de repleção de 30 dias, sendo o delineamento inteiramente casualizado com 3 tratamentos de 8 animais cada, assim distribuidos: Dieta regional (DR), Dieta regional + zinco $(\mathrm{DR}+\mathrm{Zn}) \mathrm{e}$ Dieta Controle.

Durante o período experimental, os animais foram mantidos em gaiolas individuais de aço inoxidável, em ambiente com umidade e temperatura controladas e constantes, com um ciclo de luz de 12 horas. Todo material utilizado foi desmineralizado,

$\mathrm{O}$ crescimento dos animais foi acompanhado durante todo o estudo por meio de pesagens semanais. A ingestão das rações, a troca de água dos bebedouros e a coleta de fezes foram acompanhadas a cada dois dias no mesmo horário.

Em todas as etapas do experimento e ao final, os animais foram sacrificados para a obtenção do material biológico para as análises.

Houve restrição alimentar apenas no dia do sacrifício e a água desionizada foi oferecida "ad-libitum".

A análise da composição centesimal da dieta e das rações seguiu as recomendações da AOAC (1984). A determinação da fração fibra foi realizada pelo Método de ASP et al., (1983), e o de fitato por colorimetria, segundo o método de THOMPSON \& 
ERDMAN (1982), modificado por LAJOLO et al.,(1991).

O teor de zinco nas rações e fêmures foi determinado em espectrofotômetro de absorção atômica, após digestão via úmida pelo método preconizado por PARKER $e t$ al.,(1967). Para o controle da análise, seguiram-se as recomendações de CORNELIS (1992), utilizando-se como material de referência a "Total Diet 1548" da NBS (National Bureau of Standards). $\mathrm{O}$ teor de zinco no plasma foi determinado diretamente nas amostras diluidas na proporção de 1:4 em espectrofotômetro de absorção atômica, segundo RODRIGUES et al., (1989).

Quanto aos teores de cálcio, ferro, magnésio, manganes e selênio da dieta regional, seguiu o mesmo procedimento quanto ao preparo das amostras, e determinados em espectroscopia de emissão atômica com plasma de argônio induzido, e o selênio foi determinado por análise de ativação com neutrons.

A determinação da atividade da álcool desidrogenase seguiu a metodologia preconizada por BERGMEYER (1975). A concen-tração de protéina foi determinada de acordo com LOWRY et al. (1951).

Para a análise estatística dos resultados, utilizou-se a análise de variância e para efeito de comparação entre as médias dos tratamentos, o teste de Tukey com $5 \%$ de probabilidade (PIMENTEL GOMES, 1987).

\section{RESULTADOS E DISCUSSÃO}

Inúmeros são os fatores dietéticos que podem interferir na biodisponibilidade de zinco.

Uma característica importante da dieta consumida pela população Manauara na ocasião do estudo, foi o alto consumo de peixes, muito difundido nesta região, que ao lado de ser uma fonte protéica de maior qualidade ainda é um fator promotor da biodisponibilidade de zinco (Tab. 1).

Portanto, a dieta estudada caracteriza-se pelo baixo consumo de hortaliças e leguminosas, além do alto consumo de peixe, pão e farinha de mandioca (SHRIMPTON \& GIUGLIANO, 1979), o que a diferencia de outras dietas da alimentação brasileira que se baseiam no alto consumo de arroz e feijão com pouca proteína de origem animal (PEDROSA \& COZZOLINO, 1990; BOAVENTURA, 1992).

Considerando a recomendação nacional de fibra alimentar de $20 \mathrm{~g} / \mathrm{dia}$ (VANNUCCHI et al.,1990), podemos inferir que a dieta regional de Manaus da mesma forma que outras dietas brasileiras analisadas possuem teores adequados (PEDROSA \& COZZOLINO, 1990; BOAVENTURA, 1992). O efeito da fibra sobre o balanço de minerais, continua a ser um assunto controverso. Há sugestões de que as fibras presentes nos vegetais podem diminuir a biodisponibilidade de zinco (NAVERT et al., 1985), entretanto, isto não tem sido consistentemente relatado em outros estudos (COSSACK et al., 1992). Por outro lado, uma alta ingestão de fibra, implica também no maior teor de fitato, uma vez que são provenientes da mesma fonte e este sim pode ter um efeito adverso sobre os minerais de interesse nutricional (SANDSTEAD, 1990).

O fitato, hexafosfato de mioinositol, é um outro fator dietético que predispõe à baixa biodispo- 
Tabela 1. Composição básica da dieta regional de Manaus, AM. (SHRIMPTON \& GIUGLIANO, 1979).

ALMENTOS

\section{Pão}

Arroz

Farinha mandioca d' água / seca

Batata doce/inglesa

Açucar

feijăo sul

Tomate

Cebola

Milho verde

Jerimum

Couve

Cheiro verde

Banana prata/maça

Abacate

Limão

Carnes: bovina/galinha

Ovos

Peixe

Leite reconstituido

óleo

Margarina

Refrigerante

Café

Sal

Condimentos (Coloral, pimenta, vinagre)
QUANTIDADE PER-CAPTA (g)

140,6

64,7

71,9

13,3

60,4

29,7

11,5

8,9

7,1

3,5

2,7

4,7

65,2

5,8

4,7

74,4

12,5

150,6

101,2

16,0

6,1

59,9

12,4

9,8

5,1

943,0 
nibilidade do zinco (FORBES et al.,1984), entretanto, o teor de fitato na dieta regional de Manaus, foi considerado baixo quando comparado com o de outras dietas (PEDROSA \& COZZOLINO, 1990; COZZOLINO, 1992).

As razões molares obtidas de fitato:zinco de 3,8 e fitato x cálcio: zinco de 38,7 estão abaixo dos valores considerados críticos para o aproveitamento de zinco da dieta. Os valores críticos sugeridos para a razão milimolar de fitato:zinco e fitato $x$ cálcio:zinco são respectivamente $>10$ e $>200$ (ELLIS \& KELSAY, 1987).

O fitato forma um complexo insolúvel com o zinco reduzindo sua biodisponibilidade. Este efeito é acentuado numa dieta rica em cálcio (FAIRWEATHER-TAIT et al., 1992), entretanto, uma das limitações da dieta regional de Manaus, é a deficiência de cálcio.

Assim, é possivel que todos esses fatores predisponentes tenham interferido favoravelmente na biodisponibilidade de zinco.

O desenvolvimento ponderal é um dos parâmetros utilizados para a avaliação da biodisponibilidade de zinco (WALLWORK, 1983).

No início do período experimental os animais apresentaram peso médio de $48,9 \pm 0,5 \mathrm{~g}$. Ao final do período de repleção, os animais dos diferentes tratamentos ganharam peso, sendo entretanto, mais pronunciado naqueles que receberam a dieta regional de Manaus, seguido da dieta regional suplementada com zinco e ração controle (Tab, 2).
Ao se comparar o consumo de ração entre os grupos, verifica-se que o grupo controle foi o que apresentou menor consumo. Entretanto, a ração controle continha um teor de zinco e de outros nutrientes que atendia as recomendações do COMMITTEE ON LABORATORY ANIMAL DIETS (1979). Uma possível explicação para o menor consumo deste grupo, seria devido ao fato da caseína utilizada para o preparo das rações ter sido lavada com EDTA para uniformizar os teores de zinco, e este procedimento pode ter afetado a palatabilidade e aceitabilidade desta ração, conforme os estudos de COSSACK \& HAMER (1987).

No que se refere ao zinco, a possibilidade de alterações bioquímicas em função de uma ingestão insuficiente ou elevada são inúmeras, uma vez que o mesmo tem uma participação importante em inúmeras enzimas e na estabilização da estrutura protéica (VALLEE \& AULD, 1990). Inúmeros trabalhos demonstram que o zinco é um fator depressivo do crescimento (SWENERTON \& HURLEY, 1968).

Embora quantitativamente em níveis limítrofes em relação as recomendações supõem-se que a quantidade existente na dieta seja biodisponível, talvez favorecida pelos fatores predisponentes da dieta regional.

A mesma consideração pode ser feita em relação à concentração de zinco nos fêmures e plasma.

Estes resultados permitem a interpretação de que a concentração de zinco existente na dieta regional de 
Tabela 2. Médias e desvios padrão do consumo de ração e ganho de peso dos animais submetidos aos diferentes tratamentos.

TRATAMENTOS

CONSUMO DE RAÇĀO (g) GANHO DE PESO

(g)

\begin{tabular}{lll}
\hline$D R$ & $388,3 a \pm 28,7$ & $135,6 a \pm 12,7$ \\
$D R+Z n$ & $346,0 a b \pm 34,2$ & $125,9 a b \pm 15,9$ \\
Controle & $303,3 b \pm 33,5$ & $99,3 b \quad \pm 16,0$ \\
\hline
\end{tabular}

* As mesmas letras seguidas no sentido vertical não diferem entre si ao nível de $p<0,05$ de probabilidade.

Manaus apresenta alta biodisponibilidade.

MURRAY \& MESSER (1981), verificaram que animais alimentados com dietas deficientes em cálcio, apresentavam um aumento na retenção de zinco dos fêmures para compensar essa deficiência. FORBES et al.,(1984) tem demonstrado que o cálcio, por si, só é capaz de reduzir a disponibilidade de zinco para deposição óssea, quando se encontra em níveis elevados na dieta, fato que não ocorreu na dieta regional de Manaus.

Como citado anteriormente o menor consumo de ração do grupo controle, pode ter interferido nos valores encontrados em relação à concentração de zinco nos fêmures e plasma neste grupo.

Segundo os resultados na Tabela 3 , a concentração plasmática de zinco foi superior nos animais que receberam a dieta regional suplementada ou não em relação ao controle. As alterações na concentração plasmática de zinco são transitórias, tendendo a atingir um equilíbrio homeostático, e são alta-mente influenciadas por uma variedade de fatores fisiológicos, tais como estresse físico, infecções, inflamação, estado hormonal, entre outros (KING, 1990).

Entretanto, as alterações observadas neste estudo, parecem ser mais decorrentes do consumo da dieta que por outros fatores, pois todos os animais foram submetidos às mesmas condições de experimento, exceto quanto as suplementações efetuadas nas rações à base da dieta regional e a ração controle a base de caseína lavada com EDTA.

No que se refere a atividade da álcool desidrogenase ( $\mathrm{ADH}$ ) no fígado dos animais, observou-se que houve uma atividade maior, $\mathrm{p}<0,05$ no tratamento da dieta regional acrescida de zinco.

A álcool desidrogenase hepática é uma metaloenzima na qual o zinco participa do grupo prostético como um estabilizador da estrutura quaternária da proteína. A remoção progressiva do zinco da álcool desidrogenase hepática causa um declínio da atividade proporcional ao nível da concentração de zinco retido pela enzima (OPPENHEIMER et al., 1967).

BORON et al., (1988) demonstraram que a atividade da álcool desidrogenase estava significativamente reduzida nos animais deficientes em zinco. 
Tabela 3. Médias e desvios padrão do teor de zinco nos fêmures e plasma dos animais submetidos aos diferentes tratamentos, no período de repleção.

\begin{tabular}{lcc}
\hline \multirow{2}{*}{ TRATAMENTOS } & \multicolumn{2}{c}{ ZINCO } \\
\cline { 2 - 3 } & Fêmures $(\mu \mathrm{g} / \mathrm{g})$ & Plasma $(\mu \mathrm{g} \%)$ \\
\hline DR & $111,7 \pm 7,7$ & $1,5 \pm 0,1$ \\
DR + ZN & $120,3 \pm 7,0$ & $1,5 \pm 0,0$ \\
Controle & $98,8 \pm 15,2$ & $0,8 \pm 0,2$ \\
\hline
\end{tabular}

* As mesmas letras seguida no sentido vertical não diferem entre si ao nivel de $p<$ 0,05 de probabilidade

Outros estudos tem demonstrado resultados conflitantes (HUBER \& GERSHOFF, 1975; SUNDARESAN et al., 1977). As discrepâncias entre estes relatos não parecem estar relacionadas ao grau de deficiência de zinco, mas podem ser devida à variação dietética, a idade dos animais utilizados nos diferentes estudos e ao procedimento metodológico (BORON et al., 1988).

Entretanto, em nosso estudo como já mencionado, o zinco não foi fator limitante, assim, se a alcool desidrogenase está correlacionada com a concentração de zinco, é possível que o teor existente no fígado e testículos dos animais que receberam a dieta regional, tenha sido suficiente para que não houvesse nenhuma alteração na atividade enzimática em relação ao grupo controle, a não ser no fígado dos animais que receberam a dieta regional suplementada com zinco (Tab, 4).

Maiores investigações são necessários para compreender o comportamento desta enzima.

\section{CONCLUSÕES}

De acordo com os parâmetros utilizados para a avaliação da biodisponibilidade de zinco conclui-se que:

- A concentração de zinco existente

Tabela 4. Atividade média da álcool desidrogenase (ADH) no fígado e testículos dos animais submetidos aos diferentes tratamentos no período de repleção.

\begin{tabular}{lcc}
\hline \multirow{2}{*}{ TRATAMENTOS } & \multicolumn{2}{c}{ ATIVIDADE DA ADH (nmol/min/mg proteina) } \\
\cline { 2 - 3 } & $51,4 \pm 13,3 \mathrm{~b}$ & Testiculos \\
\hline DR & $78,8 \pm 10,9 \mathrm{a}$ & $23,7 \pm 2,6 \mathrm{a}$ \\
DR + ZN & $57,4 \pm 13,6 \mathrm{~b}$ & $21,1 \pm 6,7 \mathrm{a}$ \\
Controle & & $21,3 \pm 3,6 \mathrm{a}$
\end{tabular}

* As mesmas letras seguida no sentido vertical não diferem entre si ao nível de $p<0,05$ de probabilidade. 
na dieta regional de Manaus, é tão biodisponível quanto a dieta regional suplementada com zinco e a ração controle à base de caseína.

- Os fatores que provavelmente mais interferiram nos resultados destes estudos foram: alto teor protéico de alto valor biológico, baixo teor de fitato, relação fitato $\mathrm{x}$ zinco e fitato $\mathrm{x}$ cálcio/zinco abaixo dos valôres considerados críticos, baixo teor de cálcio, fibra de acordo com a recomendação.

\section{AGRADECIMENTOS}

Ao $C N P q$ e a FAPESP, pelo auxílio financeiro, ao Sr. João da Penha e Tereza C. C. Barreto, pelo auxílio técnico.

\section{Bibliografia citada}

ASP, N.G., JOHANSSON, C.G., HALLMER, H., SILJESTROM, M. 1983. Rapid enzymatic assay of insoluble and soluble dietary liber. J. Agric. Food Chem., Washington, v. 31, p. 476-482.

ASSOCIATION OFFICIAL ANALYTICAL CHEMISTS. 1984. Official methods of analysis. 14. ed. Arlington. 1141p.

BERGMEYER, H.U. 1975. Methods of enzimatic analysis. 2. ed. Academic Press. p. 139-141.

BOAVENTURA, G.T.1991. Biodisponibilidade de selênio na dièa regional de Mato Grosso. São Paulo, 80p. Dissertação de Mestrado, Faculdade de Ciências Farmacêuticas, USP.

BORON, B., HUPERT, S., BARCH. D.H., FOX, C., FRIEDMAN, H., LAYDES, T.J., MOBNHAN, S, 1988. Effect of zinc deficiency on hepatic enzymes regulating vitamin A status. J. Nutr: Philadelphia. v. 118, p. $995-1001$.

COMMITTEE ON LABORATORY ANIMAL DIETS/ ASSEMBLY OF LIFE SCIENCES - NATIONAL RESEARCH COUNCIL. 1979. Control of diets in laboratory animal experimentation. Nutr: Abstr: Rev., Slough, v.49, p.413-419.

CORNELIS, R. 1992. Use of relerences materals in trace element analysis of foodstuffs. Food Chem., Barking, v. 43, p. 307-13.

COSSACK, Z.T., HAMER, VENSEN, C.J.A. 1992. Evalutation of the EDTA- washed diet for use in the experimental production of zinc deficiency in human subjects. Int. J. Vit. Nult: Res., Bern, v. 57 , p. $99-102$.

ELLIS, R., KELSAY, J.L., REYNOLDS, R.D., MORRIS,E.R.,MOSER,P.B., FRAZIER, C.W. 1987. Phytate: zinc and phytate $x$ calcium: zinc millimolar ratios in self-selected diets of Americans, Asian, Indians and Nepalese, I. Am. Diet. Assoc., Chi(ago), v, 87, p. 1043-47.

FAIRWEATHER-TAIT, S.J., FOX, T.E., SHARF, S.G., EAGLES, J., KENNEDY, H. 1992. Zinc absorption in adult men from a chicken sanduich made with white or wholemeal bread, measured by a double-label stable-isotope technique Br. J. Nutr:, London, v. 67, p. 41119.

FORBES, R.M., PARKER, J.M., ERDMAN Jr, J.W. 1984. Effects of dietary phytate calcium and magnesium levels on zinc bioavailability to rats. $J$. Nutr: Bethesda, v. 114, p. 1421 - 25.

HUBER, A. M., GERSHOFF, S. N. 1975. Ellects of zinc on the oxidation of retinol and ethanol in rat, J.Nut:; Plikedelphia, v. 105, p. 1486-1490.

KING, J.C. 1990. Assesment of zinc status. J. Nutr:, Philadelphica, v. 120, p. 1474 79.

LAJOLO, F. M., MARQUEZ, U. M. L., FILISETTI-COZZI,R.M.C.C.. McGREGOR, I. I991. Chemical composition and toxic compounds in rapeseed (Brasica napus, L.) eultivars grown in Brazil. J. Agric: Food Chem., Washington, v. 39, n. 11, p. 1933-1937

LOWRY, O.H., ROSEBROUGH, N.J., FARR, A.L., RANDALL. R.J. 1951. Protein measurement with the folin phenol re- 
agent. J. Biol. Chem., Baltimore, v. 193, p. 265-275.

MILLS, C.F. 1985. Dietary interactions involving the trace elements. Annu. Rev. Nutr. Palo Alto, v.5, p. 173-93.

MURRAY, E.J., MESSER, H.H. 1981. Turnover of bone zinc during normal and accelerated bone boss in rats. $J$. Nutr: Philadelphia, v. 111, p. 1641-47.

NAVERT, B.. SANDSTROM, B,, CEDERBLAD, A. 1985. Reduction of the phytate content of bran by leavening in bread and its effect on zinc absorption in man. $\mathrm{Br}$. J. Nutr., London, v. 53, p. $47-53$.

ESTREICHER, P., COUSIN, R.S. 1985. Copper and zinc absorption in rat: mecanism of mutual antagonism. $\%$ Nutr: Philadelphia, v. 115, p. 159-66.

OPPENHEIMER, H.L., GREEN, R.W., MCKAY, R.H. 1967. Function of zinc in horse liver alcohol dehydrogenase. Arch. Biochem. Biophys, New York, v. 119 , p. 552-59.

PARKER, M.M., HOMOLLER, F.L., MAHLEN, D.J. 1967. Determination of copper and zine in biological material. Clin. Cliem., Winston-Salem, v. 13, p. 40-42.

PEDROSA, L.F.C., COZZOLINO, S.M.F. 1990. Biodisponibilidade de zinco em dieta regional do Nordeste. Rev: Farm. Bioquint, Univ. S. Paulo, São Paulo, v. 26, p. 123-133.

PIMENTEL GOMES, F. 1987. Curso de estatística experimental.12.ed. Piracicaba. 467p.

PRASAD, A.S. 1969. A century of research on the metabolic role of zinc. Am. J. Clin. Nutr, Bethesda, v. 22, p. 1215-21.

RODRIGUES, M.P., NARIZANO, A., DEMEZYLO, V., CID, A. 1989. A simples method for the determination of sinc haman plasma levels by flame atomic absorption spectrophotometry: At. Spectrosc., Norwalk, v. 10, p. 68-70.
SANDSTEAD, H.H. 1990. Fiber, phytates, and mineral nutrition. Nutr. Rev., New York, v. 50, p. 30-31.

SHRIMPTON, R., GIUGLIANO, R. 1979. Consumo de alimentos e alguns nutrientes em Manaus, 1973-74, Acta Amazônica, Manaus, v. 9, n.1, p. 117 141.

SHRIMPTON, R., FRANÇA, T.S., ROCHA, Y.R., GOLDEN, M.H.N. 1983. Estudo sobre o estado nutricional em relação ao zinco na Amazônia. I níveis de zinco no soro e ingestão de zinco em operários de Manaus. Acta Amazônica, Manaus, v. 13, p. 773-94.

SUNDARESAN, P.,R., COPE, F.O., SMITH, J.C. Jr. 1977. Influence of zinc deficiency on retinal reductase and oxidase activities in rat liver and testes. J. Nutr: Philadelphica, v. 107, p. 2189 - 97.

SWENERTON, H., HURLEY, L.S. 1968. Severe zinc deficiency in male and female rats. J. Nutr, Philadelphia, v. 104, p. 8-18.

VALLEE, B.L., AULD, D.S. 1990. Zinc coordination, function and structure of zinc enzyme: and others proteins. Biochem. Washington, v. 29 , p. $5647-59$.

VANNUCCHI, H., MENEZES, E.W., CAMPANA, A.O., LAJOLO, F.M. 1990. Aplicą̧öes das recomendaçôes nutricionais adaptadas à população brasileira. Ribeirão Preto: Legis Sima, p. 156.

YUYAMA, L.K.O. 1993. Estudo da interação de zinco e vilamina $A$ em ratos recebendo una dieta regional de Manaus, AM. Efeito da Suplementação com pupunha (Bactris gasipaes H.B.K.) vitamina $A$ e zinco. São Paulo, 130p. Tese de Doutorado - Faculdade de Ciências Farmacêuticas-USP. 